\title{
As sociabilidades necessárias ao capital: o trabalho em migalhas no contexto da pandemia da Covid-19
}

The sociability demanded by capital: labor in crumbs during the COVID-19 pandemic

\author{
Angela Santana do Amaral*
}

\begin{abstract}
Resumo - Este texto discute as configurações do trabalho e as sociabilidades construídas pelo capital na fase atual da sua acumulação, destacando o contexto da pandemia, seus efeitos sobre o mercado de trabalho e as renovadas estratégias de gestão, controle e disciplinamento da força de trabalho. Analisa as determinações gerais da crise capitalista e os mecanismos de recomposição do seu domínio, através do trabalho mediado pelas tecnologias de informação e comunicação e formas de superexploração da força de trabalho que combinam o moderno e o arcaico. Nesse contexto, considera que a ampliação da informalidade e precariedade na sociedade contemporânea bem como as ideologias que orientam a formação de um trabalhador de novo-tipo, constituem os vetores que determinam os modos de ser, pensar e agir das classes trabalhadoras.

Palavras-chave: trabalho; sociabilidade; crise capitalista; pandemia; precariedade.
\end{abstract}

\begin{abstract}
This article discusses sociability and labor configurations built by capital in the current phase of its accumulation, highlighting the context of the pandemic, its effects on the labor market and the renewed strategies of management, control, and disciplining of the workforce. It analyzes the general determinations of the capitalist crisis and the mechanisms of recomposition of its domain, through the work mediated by the information and communication technologies and forms of overexploitation of the workforce that combine the modern and the archaic. In this context, it considers that the expansion of informality and precariousness in contemporary society, as well as the ideologies that guide the formation of a new type of worker, constitute the vectors that determine the ways of being, thinking, and acting of the working classes.
\end{abstract}

Keywords: labor; sociability; capitalist crisis; pandemic; precariousness.

\footnotetext{
* Doutora pela Universidade Federal do Rio de Janeiro. Docente do Departamento de Serviço Social da Universidade Federal de Pernambuco. E-mail: angela.amaral@ufpe.br. ORCID: https://orcid.org/0000-0003-2038-1296.
} 


\section{Prólogo}

La competência significa, em este tipo de capitalismo, el aplastamiento inauditamente feroz del espíritu empreendedor, de la energia, de la iniciativa audaz de la massa de la población, de su inmensa mayoría, del 99 por 100 de los trabajadores; significa también la sustitución de la emulación por la pillería financiera, el nepotismo, el servilismo en los pedaños más elevados em la escala social. (Lenin, 27 de dezembro de 1917).

Um ano após a explosão da pandemia de Covid-19, no mundo e no Brasil, o cenário da tragédia sanitária que se alastra sobre todos os quadrantes do planeta revela, em números e nas agravadas expressões da questão social, a regressão civilizatória que o capitalismo impôs à classe trabalhadora, historicamente. Estamos diante de uma crise de dimensões inimagináveis, muito embora seja esta mais uma das crises imanentes da dinâmica do capital, dos seus modos de produção e reprodução da vida social.

No momento em que escrevemos este texto, segundo dados da Organização Mundial de Saúde (de março de 2021), o mundo alcança mais de 118.621,498 de infectados pelo vírus e 2.631,397 mortos (OMS, 2021). No Brasil, ao completar um ano após a descoberta do primeiro caso, já totalizamos mais de 260 mil mortos (23\% da população mundial), 10,7 milhões de infecções (18\% da população mundial) - sem contar as subnotificações -, e o registro de uma média móvel de óbitos acima de 1500.

A célere propagação da doença no país é ainda mais agravada pela disseminação de ideias e comportamentos negacionistas e irracionalistas, por parte do governo federal e do seu representante máximo, pelo descaso e pela falta de investimentos no sistema público de saúde e na política de ciência e tecnologia. Além disso, também pelas precárias condições econômicas e sociais da população trabalhadora, que se deterioram, vertiginosamente, a ponto de inviabilizar o atendimento às necessidades mínimas de reprodução da força de trabalho.

A nosso juízo, está em curso um projeto de destruição, não só física, que caminha pari passu à devastação ambiental e à violenta extração da riqueza produzida, mas de possibilidades de construção de uma sociabilidade superior, que supere as relações de exploração e as opressões de todo tipo constitutivas do sistema capitalista. Este projeto se acelera e se agrava com a pandemia, e é precisamente nesse contexto e nessa fase de acumulação capitalista que avança a ofensiva do capital sobre o trabalho, com vistas a assegurar suas rentabilidade e produtividade, necessárias à sua dominação. 


\section{Transformar a objetividade em subjetividade burguesa: a dinâmica mundial de recomposição do capital}

Essa permanente busca por mais lucros, produtividade e dinamização das forças produtivas é potencializada por inciativas e estratégias para manter e atualizar os pilares de sustentação da dinâmica capitalista: a propriedade privada, a divisão do trabalho e a exploração. Em períodos de crise, exige-se o sacrifício de todos e a socialização das perdas, as quais precisam ser assimiladas como parte de um projeto universal.

Sustentamos que a história do capitalismo é a história das suas reestruturações e das respostas que as classes dominantes engendram com a finalidade de estabelecer renovadas bases materiais e "espirituais" para sua expansão, reprodução e acumulação. Estas bases estão associadas, portanto, à articulação entre economia e política; entre objetividade e subjetividade. Como dizia Gramsci (2001, p. 266), "os novos métodos de trabalho são indissolúveis de um determinado modo de viver, de pensar, de sentir a vida: não se pode obter sucesso em um campo sem obter resultados tangíveis no outro".

Apreender este processo significa conhecer como a burguesia internacional e seus operadores locais se movem para obtenção de hegemonia na sociedade. Nesse sentido, estamos assistindo a que este movimento, coordenado pelo capital fictício, tem uma importância vital para os capitalistas no quadro da pandemia, dado que a crise que já estava em curso ganha novos contornos e os interpela a "sofisticar" os mecanismos já existentes de exploração da força de trabalho, que atravessam a totalidade do circuito produtivo.

Embora consideremos que a crise capitalista afeta distintamente os Estados-Nação, vale dizer que existem elementos gerais que a determinam. Os mecanismos e estratégias de recomposição assumem especificidades, especialmente nos países de capitalismo dependente e periférico, onde as relações capitalistas são muito mais predatórias. Nestas, as condições de acumulação e expansão do capital respondem por outros complexos que se relacionam às formações sócio-históricas desses países, à conformação das burguesias e suas frações, à adoção de modelos econômicos assumidos pelos governos para o desenvolvimento do capitalismo.

Com efeito, as bases da divisão internacional do trabalho e os mecanismos de enfrentamento às crises possuem consequências avassaladoras sobre as periferias. As contradições do capitalismo são expostas nas singularidades históricas, sendo tratadas, objetivamente e subjetivamente, como momento necessário à valorização do valor. Para Katz (2010, p. 118)

[...] en las etapas de crisis las regiones periféricas son las principales víctimas de la declinación tendencial de la tasa de ganancia, pero durante las fases de prosperidad también costean parte de la com- 
pensación de ese desequilibrio. Contrarrestan la caída porcentual del beneficio por vía comercial (deterioro por los términos de intercambios), financiera (especulación)e industrial (explotación de una fuerza de trabajo abundante).

A crise capitalista - que é estrutural e própria dessa dinâmica histórica - desenvolve um conjunto de relações que envolvem a posição dos países no mercado mundial, a correlação de forças presentes entre as classes, o nível de desenvolvimento das forças produtivas e de suas relações internas e externas de intercâmbio (MIRANDA, 2018). A esse respeito, Marx (2017, p. 283) explicita as limitações específicas da produção capitalista e as condições sociais pelas quais a força de trabalho produz mais trabalho e se torna fonte de capital adicional:

Estando pressuposta a existência dos meios de produção necessários, isto é, de uma acumulação suficiente de capital, a criação de maisvalor pode encontrar apenas dois obstáculos: a população trabalhadora, se está dada a taxa de mais-valor, isto é, o grau de exploração do trabalho; e o grau de exploração do trabalho, se está dada a população trabalhadora. O processo de produção capitalista consiste essencialmente na produção de mais-valor representado pelo mais-produto, ou na alíquota das mercadorias produzidas, na qual o trabalho nãopago está objetivado. Não se pode jamais esquecer que a produção do mais-valor - e a reconversão de parte dele em capital (ou seja, a acumulação) constitui parcela integrante dessa produção do maisvalor - é a finalidade direta e o motivo determinante da produção capitalista. Razão pela qual não se deve apresentá-la como o que ela não é, a saber, como uma produção que tem por finalidade direta o desfrute ou a criação de meios de desfrute para o capitalista. [...] O mais valor estará produzido tão logo a quantidade espolíável de mais-trabalho estiver objetivada.

O fato de essas relações de compra e venda da força serem aqui recuperadas nos conduz ao debate das condições concretas sob as quais se pode analisar a participação da periferia do capitalismo na dinâmica da acumulação e valorização do valor. Durante a pandemia da Covid-19, e mesmo em períodos anteriores, vimos que o estancamento da ordem econômica mundial produziu novas fontes de capital adicional, deslocando parte da força de trabalho para a esfera dos serviços, ao passo que manteve e aumentou uma superpopulação relativa disponível para o capital.

Estamos diante, portanto, de uma maior concentração e centralização do capital e de uma massa de trabalhadores livres, disponíveis e em grande escala que expressam as desigualdades sociais inerentes à dinâmica capitalista. Daí analisarmos o fato de o desenvolvimento deste par concentração-centralização só ser possível com a crescente desvalorização das forças produtivas, especialmente o trabalho, a força produtiva por excelência, na acepção marxiana. 
A concreção das múltiplas formas de materialidade e as consequentes alternativas criadas para a crise atual que o capitalismo enfrenta, implica, necessariamente, em explorar a força de trabalho em níveis brutais para incrementar a produtividade e a rentabilidade do capital. Miranda e Granemann (2020, p. 23), ao tratarem das formas contemporâneas de extrair mais-valor da riqueza socialmente produzida e privadamente apropriada - vale dizer, com a anuência do Estado -, assinalam um conjunto de deslocamentos dos capitais que acabam por se expandir e recuperar a capacidade da burguesia de reorganizar os processos econômicos e os aparatos jurídicoformais que lhe sustentam:

[...] a tentativa de recompor a taxa de lucro pelo brutal aumento do grau de exploração da força de trabalho, assim como a maior liberdade para o capital buscar onde queira espaço para se expandir (nos mercados financeiros, nos ganhos comerciais e custos mais vantajosos para a produção por todo o globo, na cessão do direito à exploração de serviços antes oferecidos pelo Estado, apropriando-se do fundo público etc.). Quando os instrumentos tradicionais à disposição do Estado para estimular a acumulação do capital industrial mostraramse ineficazes, revelou-se, como demonstrara Marx, que o desenvolvimento das forças produtivas, dada a lógica individual da busca por vantagens concorrenciais, acabara por reduzir a própria capacidade da produção do mais-valor.

As funções econômicas exercidas pelo Estado são expandidas, na medida em que este articula os interesses da acumulação, facilita a entrada de negócios e contratos no país, coordena as ações de desregulamentação das legislações, entrega o fundo público à sanha do capital fictício - através da privatização de empresas, compra de ativos financeiros -, presta socorro às empresas quebradas e viabiliza os lucros exorbitantes dos bancos e de outros agentes financeiros. Assim, a dinâmica econômica submete-se à ação predatória do capital fictício, o que, em tempos cada vez mais curtos, provoca quadros de crise cada vez mais graves, os quais só podem ser superados com a intensificação da ação destrutiva do capital, com maior exploração do trabalho e, consequentemente, com o acirramento da barbárie social.

A saída para o colapso econômico e social tem sido orientada por medidas ultraneoliberais, no campo econômico, como as já acima mencionadas. Além disso, do ponto de vista ideopolítico, é efetivada através de diversas estratégias, afiançadas pelo Estado e suas instituições, mediante as contrarreformas e a regulação política do mercado do trabalho - vide as legislações em vigência no Brasil que instituíram formas brutais de precarização da vida e do trabalho, além do discurso do empreendedorismo, que, na prática, significa autoexploração do trabalhador.

A regressão dos direitos do trabalho, bem como a consequente explosão da informalidade e do desemprego, expôs o acirramento das desigualdades no país, encobertas pela constituição da figura do empreendedor, 
sob argumentos político-ideológicos amplamente disseminados pela grande mídia e por um Congresso Nacional hegemonizado por grupos conservadores, reacionários e articulados a setores do empresariado. Aliás, os interesses dos grupos empresariais foram contemplados através das propostas apresentadas pela sua representação máxima - a Confederação Nacional da Indústria (CNI; 2012).

Com esse perfil parlamentar, a mobilização de mecanismos de consentimento que justificavam a necessidade de modernização e flexibilização do trabalho, junto à débil resistência dos movimentos sociais e sindicais - já golpeados pelos constantes ataques do governo Temer (2017) -, selou-se o desmonte da proteção social do trabalho. ${ }^{1}$

Após aprovação da Reforma Trabalhista - Lei no 13.467/2017 -, os ataques sobre os direitos sociais não cessaram e o projeto de desfinanciamento das políticas sociais já em curso foi acelerado, em uma tentativa exitosa de articular o equilíbrio entre reformas econômicas e reformas políticas.

À medida que o conjunto das legislações introduzem novas modalidades de regulação do trabalho, o mercado de trabalho se revela como mais flexível e informal do que estruturalmente já o era. O capitalismo dependente brasileiro, ainda que tenha conseguido se integrar ao mercado mundial e às suas dinâmicas em uma condição subordinada, forjou um modelo de desenvolvimento. Porém, as características rurais e escravocratas da nossa formação sócio-histórica, além de produzirem uma burguesia incapaz de impulsionar um projeto nacional, orientaram a sua economia sob bases predatórias, em que "o arcaico alimentava o moderno, e este promovia as formas de aproveitamento daquele" (OLIVEIRA, 2018, p. 73).

O trabalho intermitente, a subcontratação, o trabalho autônomo, o trabalho em home office, a ampliação da jornada de trabalho, a negociação de acordos individuais para ampliação das horas trabalhadas e a flexibilidade das formas remunerativas de trabalho são partes de estratégias que visam produzir um sujeito-trabalhador que gestione individualmente seu tempo de trabalho e assuma os riscos decorrentes das suas atividades de forma natural.

Do ponto de vista da saúde e da seguridade no trabalho, os efeitos também são devastadores, posto que as atividades insalubres e a pauta do tempo de descanso podem ser negociadas sem a mediação das representações sindicais: todas essas questões possuem um impacto negativo no âmbito das relações de trabalho, na reprodução da vida dos/as trabalhadores/as e nas instituições públicas que mediavam e asseguravam a proteção ao trabalho. A título de ilustração, o trabalho intermitente, apre-

\footnotetext{
${ }^{1}$ Aqui recordamos que inúmeras medidas e legislações que modificavam a proteção ao trabalho já estavam em curso no governo de Dilma Rousseff, sob a pressão das classes dominantes que exigiam um brutal ajuste fiscal, diminuição dos gastos públicos e eliminação de direitos. Critérios mais restritivos de acesso à concessão de benefícios, a exemplo do seguro-desemprego, foram implementados.
} 
sentado como uma grande novidade nos termos da Reforma Trabalhista, remunerou os trabalhadores em $\mathrm{R} \$ 637,00$ mensais, em média, durante o ano de 2019. Os dados de pesquisa realizada pelo Dieese (2020) revelam que, em quase $22 \%$ dos contratos, a renda gerada por esse tipo de trabalho foi mínima ou inexistente.

\section{As matrizes das novas sociabilidades e o trabalho no contexto da crise}

Na caracterização de Michael Roberts (2016), esse período de "larga recessão" aprofunda globalmente os efeitos das políticas de ajustes e austeridade conduzidas pelas agências multilaterais de desenvolvimento e pelos governos nacionais. Para o autor, não se trata de uma crise final porque "quedan seres humanos em el mundo para explotar, y continuamente aparecen nuevas innovaciones tecnológicas que pueden proporcionar um nuevo ciclo de Kondratiev que expande el valor y la plusvalía" (ROBERTS, 2016, p. 296). A produção em larga escala da desigualdade e a reafirmação do princípio de que o capitalismo é, ao mesmo tempo, produção de riqueza e de pobreza: é dessa forma que ele mesmo cria as suas contradições.

Segundo dados do jornal El País, em plena pandemia, as maiores fortunas do planeta explodiram. Os 20 indivíduos mais ricos do mundo acumularam um patrimônio de 1,77 trilhão de dólares (8,83 trilhões de reais), o que representa um crescimento de $24 \%$ em relação a 2019 . Somente a Amazon, que se beneficiou nesse período pelo impulso do comércio digital (e-commerce), teve um rendimento de $75 \%$ nas bolsas, fazendo seu valor de mercado subir a 1,6 trilhão de dólares (EL PAÍS, 2021).

O informe da Oxfam (2020), no seu relatório Poder, lucros e pandemia, lançado em setembro de 2020, demonstra que as grandes corporações internacionais, que nesse período da pandemia - ainda que não restrito a ele - auferiram vultosos lucros, tornaram-se as mais rentáveis do mundo de um conjunto de 32 empresas pesquisadas. Os dados expõem um disparado crescimento do faturamento destas empresas, indicando ser este superior à média obtida entre 2016 e 2019. Somadas, elas devem faturar US\$ 109 bilhões a mais durante a pandemia do que na média dos quatro anos anteriores, que já haviam sido bastante lucrativos. Como muitos dos bilionários do mundo também são alguns dos maiores acionistas dessas empresas, a fortuna dos 25 mais ricos entre eles aumentou em impressionantes US\$255 bilhões só entre meados de março e final de maio.

Em outro relatório publicado pela organização em janeiro de 2021, O vírus da desigualdade, complementa-se que a riqueza individual acumulada pelos bilionários do planeta desde o início da crise sanitária 
provocada pela pandemia, até dezembro, foi de US\$3,9 trilhões. A riqueza total que eles apropriaram foi de US\$11,95 trilhões. Isso significa o equivalente ao que os países que formam o grupo do G20 investiram para enfrentar a pandemia (COSTA, 2021).

Os dados da Organização Internacional do Trabalho (OIT, 2020) também ratificam a dimensão do deterioro do mercado de trabalho: são mais 400 milhões de empregos perdidos e uma previsão de que mais do que 430 milhões de pequenos negócios estão sob risco de falência. Não é necessário dizer que a perda de empregos vem afetando mais mulheres do que homens. E muito mais mulheres negras que vivem nas periferias. Estimase que, em todo o mundo, $54 \%$ dos empregos perdidos serão de mulheres. Na pandemia, é notório que as trabalhadoras/mães aumentaram sua carga de trabalho - diga-se de passagem, não remunerado -, cabendo-lhes, ainda, a tarefa de cuidados com familiares.

A crise, agravada com a pandemia da Covid-19, é atravessada pelo drama da impossibilidade de termos vacina para toda a população ${ }^{2}, 0$ crescimento dos negacionismos, o espraiamento de novas cepas do vírus, um descontrole estatal na gestão da doença, uma ascensão desmedida da extrema direita, misticismos e fundamentalismos, além da massificação de instrumentos midiáticos que estimulam o consumo e a moralização das classes trabalhadoras - conformando uma profunda miséria cultural e um novo tipo humano.

A tragédia social não tem fim. A destrutividade do mercado de trabalho é patente. Segundo a PNAD Contínua (IBGE, 2020), o Brasil terminou o ano de 2020 com o fechamento de 7,336 milhões de postos de trabalho. A taxa de desemprego foi a maior, se considerarmos a série histórica medida pelo instituto: média de 13,5\%, representando 13,415 milhões de desempregados. Nessa pesquisa, destaca-se, inclusive, a diminuição do setor informal, que registrou uma taxa de $38,7 \%$ - o que equivale a 33,3 milhões sem carteiras assinadas, em relação a 2019, quando esta taxa representava $41,1 \%$. Para estes/as trabalhadores/as, o Auxílio Emergencial ${ }^{3}$ significou a sobrevida por alguns meses, muito embora seu fim, em dezembro de 2020, deva levar 3,4 milhões de brasileiros para a extrema pobreza (GUSSEN; MARTINS, 2021).

Nesse contexto de informalização e precariedade do trabalho, agregado à pandemia, o capitalismo mostrou aos trabalhadores a sua resposta ao enfrentamento ao desemprego: tornar o informal um estado permanente. $\mathrm{O}$ trabalho subordinado a plataformas digitais, organizado na esfera dos serviços e das novas necessidades dos consumidores em tempos de isolamento social, ganha força, adesão e visibilidade, transformando-se em uma modalidade estruturada pelas inovações tecnológicas e marcada

\footnotetext{
${ }^{2}$ Ver Hucker e Palumbo (2020).

${ }^{3}$ Ver Boschetti e Behring (2021): Assistência Social na pandemia da Covid-19: proteção para quem? Artigo do n. 140 da Revista Serviço Social e Sociedade.
} 


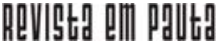

\} AS SOCIABILIDADES NECESSÁRIAS - AMARAL, A. S. \}

DOI: 10.12957/REP.2021.60291

por uma precariedade vital dos sujeitos que estão encurralados na teia dos algoritmos que agora os organizam.

Tudo isso vem acompanhado de um léxico renovado - mas não neutro -, a exemplo da noção "trabalhabilidade", cujo suposto é o de vincular a aquisição de competências e habilidades individuais e socioemocionais com as possibilidades de ocupar postos incertos de trabalho e, assim, diferenciar-se no competitivo mercado de trabalho. Vale dizer que estas condições, ademais de impor um acesso restrito aos conhecimentos e a uma formação sólida, empurram a classe trabalhadora para enredar-se em atividades e tarefas caracterizadas pelo trabalho simples, e/ou a integrar-se ao ambiente dos empreendedores.

No entanto, os/as trabalhadores/as assalariados/as não fogem a essa regra da precariedade, posto que ela é inerente aos processos de exploração da força de trabalho. No momento em que esses/as trabalhadores/as, em grande medida, estejam na condição de teletrabalho na pandemia que ainda se alastra, o rebaixamento das suas condições de vida e de trabalho e o medo do desemprego se manifestam vigorosamente. A ausência de distinção entre os espaços de produção e reprodução da vida, as pressões por metas a serem atingidas e a falsa autonomia de gerir o tempo de trabalho são elementos desestabilizadores em comparação às sociabilidades construídas pelos coletivos de trabalho no mesmo espaço.

Os estudos de Linhart (2016, p. 68) recorrem à noção de "precariedade subjetiva" para expressar as tensões e contradições de um trabalho que responsabiliza o trabalhador pelas soluções organizativas para alcançar os objetivos empresariais, em termos de qualidade e produtividade.

[...] podemos describirla con el sentimiento de no dominar el trabajo y de tener que realizar esfuerzos sin parar para adaptarse...de no disponer de recursos en casos de problemas de trabajos graves, ni por parte de jerarquía [...] ni por parte de los colectivos laborales que se han desmembrado con la individualización sistemática de la gestión de los asalariados y su puesta en competencia.

As atividades mediadas pelas tecnologias, sob o discurso da liberdade, do autoemprego e da autogestão do trabalho, não parecem significar o controle de si mesmo e do seu tempo de trabalho, como prometem. Essas atividades devem, necessariamente, ser entendidas, no seu conteúdo e forma, como dinâmicas que têm favorecido um modelo econômico e desigual de trocas, a superpopulação relativa em escala global e a crescente desvalorização da força de trabalho.

Sob esse aspecto, uma das chaves interpretativas para compreender o trabalho contemporâneo é que, mesmo com a crise, as empresas capitalistas encontraram formas e estratégias para extrair mais-valia dos seus/ uas trabalhadores/as, impulsionando modos de superexploração da força de trabalho e expropriando os saberes e qualificações dos/as trabalhadores/ 


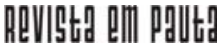

I AS SOCIABILIDADES NECESSÁRIAS - AMARAL, A. S. \}

DOI: 10.12957/REP.2021.60291

as. Ao fazer isso, articulam, em um mesmo movimento, o moderno e o precário, na tentativa de redirecionar seus negócios e obter lucratividade, mesmo em tempos de desemprego e de pandemia.

Inúmeros são os exemplos desse processo: em Pernambuco, a crise do setor têxtil, particularmente a vigorosa produção de jeans no Polo de Confecções do Agreste, foi enfrentada com a reorientação do processo produtivo para fabricação de batas, máscaras e equipamentos de proteção individual para os profissionais de saúde do estado. Para tanto, o trabalho simples adquiriu centralidade, na medida em que "qualquer indivíduo pode ser adestrado, e que deve executar de uma ou de outra forma [...]" (MARX, 1982, p. 33). Com o assentimento do Estado, pequenos e médios empresários garantiram seus lucros e protegeram seus negócios.

As plataformas digitais, a internet das coisas, a inteligência artificial e a economia de compartilhamento são denominações e recursos que se expandem e passam a integrar diversas dimensões da vida social, sob a marca da inovação, do desenvolvimento autônomo dos sujeitos, dos aprendizados individualizados e das suas experiências práticas. Avança-se sobre a necessidade de formar uma classe trabalhadora de modo que esta esteja disponível para o mercado de trabalho dos novos tempos: instável, informal, flexível, sem proteção social. Em outros termos, uma classe trabalhadora pronta para realizar qualquer tipo de trabalho e/ou se manter à disposição dos representantes do capital, os quais pretendem convertê-la em trabalhadores intermitentes ou mesmo em empreendedores.

A desidentidade de classe é, portanto, um vetor central da dominação burguesa nesse momento. As classes dominantes, ao apostarem no rebaixamento das condições de reprodução dos grupos subalternos, na desorganização dos coletivos, em mecanismos sofisticados e sutis de subsunção do trabalho ao capital, tecem suas estratégias de hegemonia adequando o trabalhador às suas necessidades atuais de acumulação. Assim, essas classes impõem pautas que integram um novo modelo, uma "nova razão de mundo" ${ }^{\prime 4}$, fundada em uma outra perspectiva de sociabilidade e em uma geração (já referida como a "geração lockdown") sem direitos garantidos e com trabalhos precários, mas incluída, através do discurso das oportunidades, da capacidade empreendedora e da autonomização/individualização dos seus projetos à parte do Estado regulador.

Às questões expostas, problematizamos o risco que o denominado capitalismo de plataforma implica sobre os modos de vida contemporâneos. A vigilância dos nossos dados, apropriados por modernos controles tecnológicos, tão bem caracterizados nos filmes Privacidade hackeada e Snowden, mostram o quanto nosso cotidiano está sendo mapeado e acompanhado por meio de sentenças matemáticas que coletam e organizam informações; essas servem de parâmetro para moldar formas de consumo, subjetividades

${ }^{4}$ Ver Dardot e Laval (2016): A nova razão do mundo. Ensaio sobre a sociedade ne 


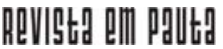

\} AS SOCIABILIDADES NECESSÁRIAS - AMARAL, A. S. \}

DOI: $10.12957 /$ REP.2021.60291

e relações sociais determinadas, a partir de interesses que exigem o aprofundamento de estudos e pesquisas sobre a formação do valor nesses trabalhos, o debate sobre o tempo de trabalho socialmente necessário, e, principalmente, sobre os novos "modos periféricos" de vida na periferia.

A importância desse debate nos confronta com um trabalhador de novo tipo que,

por la escasez de trabajo assalariado, hay um peligro mucho mayor que en vez de unirse los ejércitos de reserva caigan en la tentación de ver a los demás como rivales y luchar por cualquier oportunidad de empleo que aparezca. Al no movilizarse sobre la base de la identidad ocupacional, no ven otra alternativa que apoyarse en las lealtades primarias de la etnicidad, la casta, la raza y el credo religioso. (BREMAN, 2015, p. 15).

No entanto, à parte as especificidades econômicas, políticas e culturais do estudo naquele continente, chamamos atenção para a tendência que se apresenta na conjuntura brasileira de generalização de um trabalho sob demanda e que tem conduzido a uma despossessão coletiva. Nesse movimento, não podemos perder de vista os interesses e as relações que estão subjacentes à reorganização do capital, das suas classes dominantes e as frações aí representadas. Essas, junto ao Estado, estão definindo - não sem resistência - e difundindo formas de controle e disciplinamento da força de trabalho do país, sob o argumento de que é nessa arena do trabalho flexível e sem travas regulatórias que se forjam sujeitos inovadores e empreendedores para dinamizar a economia e incidir sobre os problemas práticos da realidade contemporânea.

A despeito das inúmeras dificuldades de organização que enfrenta a classe trabalhadora, germes de resistência florescem em plena pandemia. As paralisações dos entregadores de aplicativos e as potencialidades de construção de formas de lutas articuladas a outros segmentos de trabalhadores são insuficientes, mas estão sinalizando para o que Gramsci (2002, p.184) nos recordava: "o velho morre e o novo não pode nascer". 


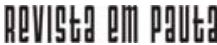

\} AS SOCIABILIDADES NECESSÁRIAS - AMARAL, A. S. \}

DOI: 10.12957/REP.2021.60291

\section{Referências}

BOSCHETTI, I.; BEHRING, E. Assistência Social na pandemia da Covid-19: proteção para quem? Revista Serviço Social e Sociedade, São Paulo, n. 140, jan./abr. 2021. Disponível em: https://www.scielo.br/pdf/sssoc/n140/ 0101-6628-sssoc-140-0005.pdf Acesso em: 1 mar. 2021.

BREMAN, J. Fuerza de trabajo paria en Asia. Madrid: Ed. Traficante de Sueños, 2015.

CONFEDERAÇÃO NACIONAL DA INDÚSTRIA. 101 propostas de modernização do trabalho. Brasília, 2012. Disponível em: http://www.portalda industria.com.br/publicacoes/2013/2/101-propostas-para-modernizacaotrabalhista. Acesso em: outubro, 2013.

COSTA, F. A desigualdade provocada pela crise capitalista. 2021. Disponível em: https://www.gposshe.com/search/label/Frederico\%20Costa. Acesso em: 29 jan. 2021.

DARDOT, P.; LAVAL, C. A nova razão do mundo. Ensaio sobre a sociedade neoliberal. São Paulo: Boitempo, 2016.

DIEESE. Boletim emprego em pauta. N. 17, dez. 2020. Disponível em: https://www.dieese.org.br/boletimempregoempauta/2020/boletimEmprego EmPauta17.html\#: :text=DIEESE\%20\%2D\%20boletim\%20emprego\%20em\%20pauta, continuam \%20na $\% 20$ gaveta $\% 20 \% 2 \mathrm{D} \%$ 20dezembro\%2F2020\&text=d os $\% 20 v \%$ C 3 $\%$ ADnculos $\% 20$ intermitentes $\% 20$ n $\%$ C3\%A3o $\% 20$ geraram $\%$ 20trabalho\%20ou\%20renda\%20em\%202019.\&text=em\%20novembro\%20 de $\% 202017 \% 20$ (Lei,do\%20contrato\%20de\%20trabalho\% 20intermitente. Acesso em: 4 jan. 2021.

EL PAÍS. Lei permite que empresas comprem vacinas, mas clínicas privadas contestam obrigação de doar ao SUS. 2021. Disponível em: https://brasil. elpais.com/brasil/2021-03-12/lei-permite-que-empresas-comprem-vacinasmas-clinicas-privadas-contestam-obrigacao-de-doar-ao-sus.html. Acesso em: 20 jan. 2021.

GRAMSCI, A. Cadernos do cárcere. Vol. 4. Rio de Janeiro: Civilização Brasileira, 2001.

GRAMSCI, A. Cadernos do cárcere. Vol. 3. Rio de Janeiro: Civilização Brasileira, 2002.

GUSSEN, A. F.; MARTINS, R. Comando Covid. Revista Carta Capital, São Paulo, ano XXVI, n. 1141, jan. 2021.

IBGE. PNAD Contínua. 2020. Disponível em: https://agenciadenoticias. ibge.gov.br/ agencia-sala-de-imprensa/2013-agencia-de-noticias/releases/29934-pnadcontinua-taxa-de-desocupacao-e-de-14-1-e-taxa-de-subutilizacao-e-de-29-0-notrimestre-encerrado-em-novembro-de-2020. Acesso em: jan. de 2021. 
HUCKER, L.; PALUMBO, D. O que as farmacêuticas têm a ganhar na corrida bilionária por vacinas. 2020. Disponível em: https://www.bbc.com/ portuguese/geral-55318843. Acesso em: 20 dez 2020.

KATZ, C. La economía marxista. Seis debates teóricos hoy. Madrid: Maya Ediciones, 2010.

LINHART, D. La emergencia de una "precariedad subjetiva" en los asalariados estables. In: TEREJINA, B. et al. (Ed.). Crisis y Precariedad Vital. Madrid: Ed. El Viejo Topo, 2016.

MARX, K. Para a crítica da economia política. São Paulo: Abril Cultural, 1982.

MARX, K. O capital: crítica da economia política. Livro III. São Paulo: Boitempo Editorial, 2017.

MIRANDA, F. Desenvolvimento desigual e mercado mundial em Marx. Rio de Janeiro: Consequência, 2018.

MIRANDA, F.; GRANEMANN, S. Crise econômica, crise sanitária: a Covid19 como instrumento da acumulação? In: SILVA, L. B.; DANTAS, A. V. (Org.). Crise e pandemia. Quando a exceção é regra geral. Rio de Janeiro: EPSJV, 2020. Disponível em: http://www.epsjv.fiocruz.br/sites/default/files/ crise_e_pandemia.pdf. Acesso em: 28 fev. 2020.

OLIVEIRA, F. Brasil: uma biografia não autorizada. São Paulo: Boitempo Editorial, 2018.

OIT. Covid-19: estimular a economia e o emprego. 30 jun. 2020. Disponível em: https://www.ilo.org/brasilia/noticias/WCMS_749513/lang_pt/ index.htm. Acesso em: jul. 2020.

OMS. Relatórios de situação. Doença por coronavírus. Março 2021. Disponível em: https://www.who.int/emergencies/diseases/novelcoronavirus-2019/situation-reports. Acesso em: 09 mar.2021.

OXFAM. Relatório poder, lucros e pandemia. Set. 2020. Disponível em: https://www.oxfam.org.br/justica-social-e-economica/poder-lucros-epandemia. Acesso em: 02 set. 2020.

ROBERTS, M. La larga depresión. Como ocurrió, por qué ocurrió y qué ocurrirá a continuación. Madrid: Ed. El Viejo Topo, 2016.

DOI: $10.12957 /$ rep.2021.60291

Recebido em 12 de março de 2021.

Aprovado para publicação em 02 de abril de 2021.

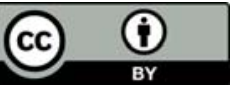

A Revista Em Pauta: Teoria Social e Realidade Contemporânea está licenciada com uma Licença Creative Commons Atribuição 4.0 Internacional. 